Est Ag 39 (2004) 501-513

\title{
La composición del De sancta uirginitate de san Agustín
}

Siempre se había aceptado la unidad de redacción de la obra De sancta uirginitate de san Agustín. Pero últimamente la han cuestionado dos estudiosos, P.-M. Hombert y G. Lettieri, sosteniendo su composición en dos etapas. Por caminos diversos, ambos llegaron a idéntica conclusión: el primero en un estudio de cronología agustiniana 1; el segundo, en otro sobre la evolución doctrinal del santo ${ }^{2}$. El argumento de fondo, sin embargo, es el mismo: la falta de unidad doctrinal que advierten en la obra.

P.-M. Hombert defiende que una primera parte de la obra fue escrita hacia el 403-404, y una segunda hacia el 412. Sus argumentos son el carácter marcadamente antipelagiano de los temas desarrollados por el santo en dicha segunda parte, sobre todo el de la impeccantia (capacidad el hombre para no pecar) y la presentación de la gracia como auxilium; determinadas y significativas coincidencias con obras de los años 411-412 (De peccatorum meritis et remisione, De spiritu et littera, epistula 140) y, por último, la constatación de que un considerable número de textos bíblicos de que se sirve en el escrito, el santo comenzó a usarlos o los usó de modo preferente una vez iniciada la controversia con Pelagio y sus seguidores ${ }^{3}$.

G. Lettieri, por su parte, aduce como prueba la existencia dentro de la obra de dos éticas sexuales diversas, que implican dos doctrinas de la gracia: mientras la primera interpreta la castidad y la humildad que debe acompanarla como disciplina, doctrina imitanda, revelada por Jesucristo maestro que se limita a enseñar y a mandar, sin dejar espacio a la gracia, la segunda sostiene que el hombre sólo puede cumplir los preceptos de Dios mediante la gracia. Esta constatación le lleva a colocar la composición de la primera parte en el 396-397, antes del libro primero, cuestión segunda, de las Quaestiones ad Simplicianum, durante cuya,composición san Agustín, según confesión pro-

1. Hombert, P.-M., Nouvelles recherches de chronologie augustinienne, Paris 2000.

2. LetTIERI, G., L'Altro Agostino. Ermenuetica e retorica della grazia dalla crisi alla metamorfosi del De doctrina christiana, Morcellina, Brescia 2001.

3. Nouvelles recherches, pp. 109-136. 
pia, experimentó un cambio profundo en su concepción de la gracia, y la segunda, después de las Confessiones a causa de la teología de la gracia que contiene ${ }^{4}$.

Coincidentes en sostener las dos etapas, ambos autores difieren no sólo en la asignación de fechas a cada una de ellas, sino también en la delimitación del texto del De sancta virginitate que les corresponde. Según Hombert, la segunda tendría su comienzo en el actual capítulo treinta y ocho $(38,39)$ y, según Lettieri, en el capítulo treinta y seis $(36,36)$. Pero, independientemente de cuál consideren que es el comienzo de la segunda parte, ambos asumen que llega hasta el final de la obra.

Damos por hecho que una parte del De sancta uirginitate fue compuesta en un segundo momento, pero no aceptamos considerarla como una «segunda parte» del escrito. Juzgamos más acertado hablar de una sección antipelagiana intercalada en la segunda parte de la obra ya completa. Expongamos las razones, examinando la segunda parte del escrito agustiniano, tal como nos ha llegado. Comenzamos con una serie de constataciones:

1. La segunda parte comienza en el capítulo treinta y uno $(31,31)$, en que san Agustín anuncia que comenzará a ocuparse de la humildad 5 .

2. El capítulo cincuenta y seis $(56,57)$ constituye el epílogo de la obra en la intención del autor. Su mismo contenido así lo deja entender 6 .

3. El capítulo cincuenta y cuatro $(54,55)$ introduce una sección conclusi$v a$, en la que san Agustín saca las conclusiones de lo anteriormente dicho. Indicador de ello es el ergo (por lo tanto) ${ }^{7}$.

4. Los capítulos del treinta y uno $(31,31)$ al cincuenta y tres $(53,54)$ contienen la motivación de la humildad que el santo presenta en el contexto de la salvaguarda de la virginidad.

\section{Motivación de la humildad (31,31-53,54)}

Si se examina esta sección, es fácil advertir que, a nivel de contenido, consta de dos partes: una primera en que el autor motiva la virtud de la

4. L'Altro Agostino, pp. 218-221. Al tener conocimiento de la tesis de Hombert, propuso dos posibilidades distintas de datación para la segunda parte, manteniéndose firme en la defendida para la primera.

5. «Unde huius muneris magnitudo..., quanto est excellentius atque divinius, tanto magis admonet sollicitudinem nostram non solum de gloriosissima castitate, uerum etiam de tutissima humilitate aliquid loqui» (XXXI,31 CSEL 41, 268, l 7 7-11).

6. «Pro modulo itaque nostro et de sanctitate..., et de humilitate..., satis locuti sumus» (LVI,57 CSEL 41, 301, I. 17-19).

7. «Si ergo nuptias contempsistis filiorum hominum, ... toto corde amate speciosum forma prae filiis hominum» (LIV,55 CSEL 41,300, 1. 9-11). 
humildad en los vírgenes con el ejemplo de Jesucristo y una segunda en que motiva la misma virtud desde la persona que ha profesado la virginidad. A nivel literario, en cambio, se puede hablar de tres partes: la primera contiene la motivación puramente cristológica; la segunda, la motivación personal, y la tercera, una combinación de ambas. La motivación cristológica ocupa los capítulos del treinta y uno al treinta y siete $(31,31-37,38)$. San Agustín recurre al ejemplo de Jesucristo, remitiendo primero al hecho de la encarnación $(31,31)$, y luego a su enseñanza $(32,32)$; de una y otra infiere la necesidad de la humildad (33,33-34,34). A continuación pone al servicio de su causa la invitación de Jesucristo a aprender que él que es manso y humilde de corazón (Mt 11,25-29) (35,35a), a cuyo hilo introduce un emotivo apóstrofe dirigido a Jesús $(35,35 b-$ $37,37) \mathrm{y}$, acto seguido, otro a quien profesa la virginidad $(37,38)$. Todos estos capítulos contienen una vigorosa motivación cristológica de la humildad.

La motivación personal ocupa los capítulos del treinta y siete al cincuenta $(37,38-50,50)$. En ellos el santo considera un triple peligro a que está expuesto quien ha abrazado la virginidad consagrada. El primero es el de creerse que no está en deuda con el Señor $(37,38-42,43)$. Tomando como hilo conductor a Lc 4,47 (a quien se le perdona poco, ama poco), el obispo de Hipona muestra que el virgen ha de admitir que se le han perdonado todos los pecados que, por gracia del Señor, no llegó a cometer, insistiendo en que la práctica de la virginidad consagrada es un don. El segundo peligro consiste en creerse superior a los casados $(43,44-47,47)$, convicción que el santo rebate con el argumento de que hay personas casadas de mayor nivel moral y espiritual que los vírgenes; en efecto, el criterio supremo es la disponibilidad para el martirio, que puede tener una persona casada y no una virgen. El tercer peligro es el de creerse libre de pecado -doctrina de la impeccantia$(48,48-50,50)$, presunción a la que san Agustín se opone citando varios textos bíblicos (Pr. 20,9; Job 14,4-5; Mt 6,12; 1 Jn 1,8-10; 1 Jn 2,1-2).

Después de exponer la motivación cristológica y la personal, el santo combina una y otra. Así en el capítulo cincuenta $(50,51)$ aparece unido el motivo de la impeccantia con el seguimiento de Cristo 8; el capítulo cincuenta y uno $(51,52)$ introduce de nuevo la comparación entre los casados y los vírgenes en el marco del seguimiento del Cordero ${ }^{9}$, y en el cincuenta y dos

8. «Sed non contendo cum eis, qui adserunt hominem posse in hac uita sine ullo peccato uiuere... Unum scio... quamlibet magni sint, non est servus maior domino suo... (Io 13,16). Et utique ille est dominus... qui dicit: venite ad me omnes, qui laboratis et discite a me. Et tamen quid discimus? Quoniam mitis sum, inquit, et humilis corde (Mt 11,27-29)» (L,51 CSEL 41, 296, 1. 10-22).

9. «Facilius sequuntur agnum, etsi non quocumque ierit, certe quousque potuerint, coniugati humiles quam superbientes virgines» (LI,52 CSEL 41, 297, 1. 12-14). 
recuerda de nuevo la humildad de Jesucristo (Mt 11,29 y encarnación) en el contexto del mayor amor (cf. Lc 4,47) ${ }^{10}$.

Si lo que acabamos de exponer lo juzgamos con criterios literarios, advertimos que san Agustín se ha servido del quiasmo. Esquemáticamente expuesto, helo aquí:

1. A los vírgenes se les ha perdonado mucho $(37,38-42,43)$.

2. Los vírgenes no siempre son superiores a los casados $(43,44-47,47)$.

3. Los vírgenes no están exentos de pecado $(48,48-50,50)$.

3. Los vírgenes no están exentos de pecado $(50,51)$.

2. Los vírgenes no siempre son superiores a los casados $(51,52)$.

1. A los vírgenes se les ha perdonado mucho $(52,53)$.

Con el capítulo cincuenta y tres $(53,54)$ se cierra la sección intercalada y la que hemos considerado segunda parte. En ambos casos, el santo lo expresa mediante una inclusión. La sección intercalada se abre y se cierra con la idea de que la hinchazón del orgullo impide entrar por el camino estrecho del Señor. Al comienzo escribía: "temor de que, por gloriarte de seguir al Cordero a dondequiera que vaya, la hinchazón de tu orgullo te impida seguirle por sus caminos estrechos" 11; y al final escribe: "humillaos en todo para hallar gracia ante Dios (cf. Si 3,18), no sea que oponga resistencia a los orgullosos (cf. Sant 4,6), humille a quienes se exaltan a sí mismos e impida pasar por sus sendas estrechas a los hinchados" 12 . La segunda sección, a su vez, toda ella centrada en la recomendación de la humildad se abre y se cierra con la cita de Sir 3,18. Al comienzo había escrito: "Una vez que quienes han profesado la continencia perpetua se hayan comparado con los casados y hayan descubierto que... estos le son inferiores ${ }^{13}$... inmediatamente han de recordar lo que está escrito: En la medida en que seas grande, humíllate en todo y halla-

10. «Quapropter hoc agite, uirgines dei, hoc agite: sequimini agnum quocumque ierit. Sed prius ad eum, quem sequimini, uenite et discite, quoniam mitis est et humilis corde... Dona eius illi seruanda committite, fortitudinem uestram ad illum custodite. Quidquid mali ipso custodiente non committitis, tamquam remissum ab illo deputate, ne modicum uobis existimantes dimissum modicum diligatis et tundentes pectora publicanos ruinosa iactantia contemnatis» (LII,53 CSEL 41, 298, 1. 7-19).

11. «Metuo... ne cum te agnum quocumque ierit secuturum esse gloriaris, eum prae tumore superbiae sequi per angusta non possis» (XXXVIII,39 CSEL 41, 280, 1. 3-5).

12 «Humiliate uos in omnibus... ne superbis resistat, ne se exaltantes humilet, ne inflatos per angusta non traiciat» (LIII,54 CSEL 41, 300, 1. 4-7). Que este capítulo pertenece todavía a la sección interpolada se deduce de que aún mantiene la comparación moral entre los vírgenes y los casados: «Ecce iam tales estis, ut professae atque seruatae uirginitati ceteris etiam moribus congruatis...» (LIII,54 CSEL 41, 299, 1. 11-11).

13. Aquí la comparación es entre los estados, no entre las personas que los profesan. 
rás gracia ante Dios $(\mathrm{Si} 3,18)$ 14; al final escribe: "Mas en la medida en que sois grandes los que lo sois en el modo indicado, en esa misma medida humillaos en todo para hallar gracia ante Dios (cf. Sir 3,18)" 15.

Llegados aquí es preciso retroceder momentáneamente. Como ya indicamos, P.-M. Hombert creía que el texto elaborado por san Agustín en la segunda etapa comenzaba con el capítulo treinta y ocho $(38,39)$ y nosotros lo hemos puesto en el treinta y siete $(37,38)$. El que hayamos presentado el mismo capítulo $(37,38)$ como integrado también en la parte correspondiente a la motivación cristológica no implica que la motivación cristológica y la personal se superpongan en el capítulo, sino que hace necesaria una división del mismo. La primera parte llega hasta «lavó los pies de sus discípulos» y cae dentro de la motivación cristológica; la segunda comienza con «Conozco la dignidad de tu condición virginal» y corresponde ya a la motivación personal. Dos argumentos cabe aducir a favor de esta división.

El primero es de carácter literario. La que hemos considerado como primera parte del capítulo treinta y siete está estructurado sobre un doble "no te envío" y un único "te envío"; un doble "no irás" y un único "irás" 16. La continuación del texto, que comienza con una ponderación del valor de la virginidad ("Conozco la dignidad de tu condición virginal") ${ }^{17}$, rompe esa estructura, y presenta otra diferente: "No te propongo..., pero temo"; "No te digo..., pero temo" 18 . Este comenzar con oraciones principales negativas se puede interpretar como una forma de continuidad con el texto anterior y de camuflar la sutura ${ }^{19}$. Esa continuidad aparece también en los personajes

14. «Cum ergo perpetuae continentiae profesores se coniugatis comparantes... compererint eos infra esse... statim ueniat in mentem quod scriptum est: quanto magnus es, tanto humila te in omnibus et coram Deo inuenies gratiam» (XXXI,31 CSEL 41, 268, 1. 11-15).

15. «Sed quanto magni estis, quicumque ita magni estis, tanto humilate uos in omnibus, ut coram deo inueniatis gratiam» (LIII,54 CSEL 41, 300, 1. 3-7). El mismo texto, sin embargo, ya había aparecido antes en la sección interpolada (cf. 43,44).

16. «Non ego te, ut discas humilitatem, ad publicanos et peccatores mitto; .... Non te ad hos mitto... Ad regem coeli te mitto...Non ibis ad eum...; non ibis ad eam..., sed ibis ad eum...» (XXXVII,38 CSEL 41, 278, 1. 20,22-279, 1.1-17).

17. «Noui dignitatem uirginitatis tuae» (XXXVII,38, CSEL 41, 279, 1. 18-19). Detrás de estas palabras se puede advertir la actitud personal de quien está ufano de su virginidad, que cuadra perfectamente con la pelagiana. Esta apreciación la confirma el que inmediatamente después indica que el virgen "se gloría" (gloriaris) de seguir al Cordero a dondequiera que va. Hasta el presente, la exaltación de la virginidad procedía siempre de san Agustín.

18. «Non tibi propono..., sed timeo...; non dico..., sed metuo...» (XXXVII,38 CSEL 41, $279,1.19-22-280,1.1-2)$.

19. Téngase en cuenta, además, que todo el capítulo treinta y ocho $(38,39)$ está centrado en el temor, en continuidad con doble temor (timeo y metuo) de la conclusión del treinta y siete. Parece lógico, pues, separar el final del capítulo treinta y siete del resto del mismo y unirlo con el treinta y ocho. 
bíblicos puestos como referentes: el fariseo y el publicano (Lc 18,9-14), y la pecadora y el Simón (Lc 7,36-50), que preceden y siguen al reconocimiento de la dignidad de la virginidad. Aparece, por último, en el mantener inicialmente la forma de apóstrofe, que, sin embargo, va diluyéndose hasta convertirse en reflexión normal.

El segundo argumento nos lo brinda el texto de Lc 7,47. En la división actual aparece en los capítulos treinta y siete, cuarenta, cuarenta y uno, cuarenta y dos, y cincuenta y tres $(37,38 ; 40,41 ; 41,42 ; 42,43 ; 52,53)$. Si, en cambio, pasamos la parte última indicada del capítulo treinta y siete, justamente aquella en la que aparece citado por primera vez en la obra Lc 4,47, al capítulo treinta y ocho $(38,39)$, es decir, si hacemos comenzar el capítulo treinta y ocho donde se ha propuesto, tenemos una secuencia apenas interrumpida. Aparece en los capítulos 38,$39 ; 40,41 ; 41,42$ y 42,43 , justamente aquellos en que san Agustín trata de quitar de la cabeza a los que profesan la virginidad la idea de que se les ha perdonado poco. Se puede argumentar que queda descolgada la referencia presente en el capítulo cincuenta y dos, pero es sólo en apariencia. Como dijimos, después de haber expuesto los tres argumentos para la motivación personal de la humildad, el santo vuelve sobre ellos, asociándolos con un motivo cristológico, pero lo hace en forma quiástica. Por esa razón, la referencia a Lc 4,47 aparece la última, separada de las anteriores.

\section{La sección conclusiva $(\mathbf{5 4 , 5 5}-55,56)$}

En esta sección sorprende el ergo («por lo tanto») inicial del capítulo cincuenta y tres: "Por lo tanto (ergo), si habéis despreciado el matrimonio humano por medio del cual engendraríais hombres, amad de todo corazón al más hermoso entre los hijos de los hombres (cf. Sal 44,3)" 20. No sorprende por sí mismo, pues nada impide a un autor sacar conclusiones de algo en un momento determinado, sino por lo distante que queda el antecedente del que extrae la consecuencia. La última vez que san Agustín ha hablado en la obra de esa renuncia al matrimonio humano fue en el capítulo cuarenta y uno con estas palabras: «así, pues, para amar con todo el ardor a aquel por cuyo amor os mantenéis libres de los lazos del matrimonio, juzgad que se os ha perdonado absolutamente todo cuanto de negativo no habéis cometido bajo su guía» $(40,41)^{21}$, y la penúltima en el treinta y ocho con estas otras: «iVirgen 
amante de la piedad y el pudor que ni siquiera en el lícito ámbito conyugal diste rienda suelta al apetito carnal, que ni siquiera para obtener descendencia transigiste con tu cuerpo mortal, que suspendiste en lo alto tus miembros terrenos con su excitación ajustándolos a los usos celestes!» $(37,38) 22$. Ahora bien, ¿cuál de los dos capítulos se constituye en el antecedente del que san Agustín saca su consecuencia? Comparando el contenido de uno y otro, todo hace pensar en el treinta y siete. Son muchos los elementos comunes entre este y el cincuenta y cuatro $(54,55)$ : la renuncia al matrimonio humano ${ }^{23}$, la renuncia a una posteridad en hijos ${ }^{24}$, la cita del Sal 44,3 ${ }^{25}$, el amor de Jesucristo ${ }^{26}$, su condición de señor y de siervo ${ }^{27}$, de creador y creado ${ }^{28}$, el desprecio que sufrió ${ }^{29} \mathrm{y}$, por último, la idea del peso del amor ${ }^{30}$. Estas coincidencias tan netas permiten suponer que, en la redacción original, el actual capítulo cincuenta y cuatro seguía inmediatamente al actual capítulo treinta y siete, exceptuada su última parte. En aquel el santo sacó las conclusiones (ergo) de cuanto acababa de decir en este. A los que, al profesar la virginidad, han renunciado al matrimonio y a una descendencia carnal, en virtud de esa

21. «Proinde... uos ut ardentissime diligatis, cui diligendo a coniugiorum nexibus liberi uacatis, deputate uobis tamquam omnino dimissum quidquid mali a uobis non est illo regente commisum» (XL,41 CSEL 41, 284, 1. 19-22 - 285, 1. 1).

22. «Non ego te, anima pia, pudica, quae adpetitum carnalem nec usque ad concessum coniugium relaxasti, quae decessurum corpus nec successori propagando indulsisti, quae fluitantia membra terrena in caeli consuetudinem suspendisti...» (XXXVII,38 CSEL 41, 278, 1. 17-20).

23. «Si ergo nuptias contempsistis filiorum hominum... uacat vobis, liberum est cor a coniugalibus vinculis» (LIV,55 CSEL 41, 300, 1. 9)- «... quae adpetitum carnalem nec usque ad concesssum coniugium ralaxasti» (XXXVII,38 CSEL 41, 278, 1. 17-18).

24. «... ex quo gigneretis filios hominum» (LIV,55 CSEL 41, 300, 1. 10) - «... quae decessurum corpus nec succesori propagando indulxisti» (XXXVII,38 CSEL 41, 278, 1. 18-19).

25. «... toto corde amate speciosum forma prae filiis hominum» (LIV,55 CSEL 41, 300, 1. 10 11) - «te mitto..., ad speciosum forma prae filios hominum...» (XXXVII,38 CSEL 41, 279, 1. 35). Este texto no vuelve a ser citado entre uno y otro capítulo, y anteriormente sólo en cap. 11,11.

26. «... amatoris uestri» (LIV,55 CSEL 41, 300, 1. 12-13) - «... ibis ad eum, qui de coelo descendit pondere caritatis» (XXXVII,38 CSEL 41, 279, 1. 14-15).

27. «... etiam in caelis dominantem et in terris seruientem» (LIV,55 CSEL 41, 300, 1. 14)«... qui dominans angelis inmortalibus non dedignatus est seruire mortalibus» (XXXVII,38 CSEL 41, 279, 1. 6-7).

28. «... creantem omnia, creatum inter omnia» (LIV,55 CSEL 41, 300, 1. 14-15) - «... per quem creati sunt homines et qui creatus est inter homines» (XXXVII,38 CSEL 41, 279, 1. 3-4).

29. «illud ipsum, quod in eo derident superbi, inspicite quam pulchrum sit (LIV,55 CSEL 41, 300,1 . 15-16) - «... ad speciosum forma prae filiis hominum et contemptum a filiis hominum... obprobria exprobrantium tibi ceciderunt super me» (XXXVII,38 CSEL 41, 279, 1. 55-6.11).

30. La frase «haec in statera caritatis adpendite» (LV,55 CSEL 41, 300, 1. 19,20) hay que ponerla en relación con «... ad eum, qui de caelo descendit pondere caritatis» (XXXVII,38 CSEL $41,279,1.14-15)$. 
opción, no les queda sin amar a Cristo cuyos títulos para ser amado, la encarnación y la pasión y muerte, recogen uno y otro texto, un poco más orgánicamente presentados en el cincuenta y cuatro que en el treinta y siete.

$\mathrm{El}$ «te envío al más bello de los hijos de los hombres»-y el «irás»-, dirigido en el capítulo treinta y siete a los vírgenes que han renunciado al matrimonio, tiene su continuidad lógica en el «amad ${ }^{31}$ de todo corazón al más bello de los hijos de los hombres» porque «vuestro corazón está libre de los lazos conyugales» del capítulo cincuenta y cuatro. Parece, pues, razonable suponer que en la redacción original se sucedían sin solución de continuidad, sin espacio para la motivación personal de la humildad que en el texto actual se interpone entre ambos capítulos.

La convicción se hace más firme al advertir que lo que ha de suscitar el amor ${ }^{32}$ de los vírgenes a Cristo es la belleza que, en el texto, se manifiesta únicamente en la humildad de Cristo -de que es prueba su encarnación y su pasión y muerte- y no en el hecho de haberle perdonado los pecados, aunque sólo sea preventivamente. Expresado en otros términos, la belleza de Cristo se manifiesta en su dimensión universal, no en la particular; o, si se prefiere, se halla en relación con la primera motivación de la humildad, estando ausente la segunda. El lector de la obra esperaba que también aquí, ya en fase conclusiva, recurriese a la idea, tan explotada anteriormente, de Lc 4,47 para motivar el amor a Jesucristo.

Se podría pensar que el capítulo siguiente, el cincuenta y cinco $(55,56)$, ofrece lo que acabamos de echar de menos. La prueba podría estar en su penúltimo punto: "No os es lícito amar poco (parum... amare) a aquel por quien no amasteis (amastis) hasta lo que os sería lícito" 33. La mención del "amar poco" podría llevar a pensar en una referencia a Lc 4,47. Pero lo excluye, de una parte, la motivación aducida para señalar la ilicitud de ese poco amor: no el que el Señor le haya perdonado mucho, sino la renuncia a otro legítimo amor humano por amor a Jesucristo. De otra parte, lo hacen poco probable razones de naturaleza filológica. Sólo hay que advertir que el adverbio latino traducido por "poco" es parum, mientras que, cuando en la obra

31. Una pequeña incongruencia: el paso del singular al plural. Pero se puede explicar fácilmente. En el capítulo treinta y siete $(37,38)$ el texto cae dentro del apóstrofe en singular que sigue al dirigido a Jesucristo $(35,35-37,37)$. En cambio en el capítulo cincuenta y cuatro $(54,55)$, concluido el apóstrofe, el santo recupera el discurso en plural usado con anterioridad (cf. 27,27ss).

32. «Amate speciosum forma prae filiis hominum» (LIV,55 CSEL 41, 300, 1. 10-11).

33. «Parum uobis amare non licet, propter quem non amastis et quod liceret» (LV,56, CSEL 41, 301, 1. 14-14). 
hace referencia a Lc 7,47, utiliza siempre modicum ${ }^{34}$. Y por no si fuera suficiente, el verbo empleado para indicar el amor es amare y no diligere, el utilizado por el santo en sus referencias a Lc 4,47, no sólo en De sancta uirginitate, sino en toda su obra. Resultaría extraño que habiendo utilizado sistemática y repetidamente en los capítulos del treinta y siete al cincuenta y tres el modicum diligere, al llegar al cincuenta y cuatro $(54,55)$ y al cincuenta y cinco $(55,56)$, recurriese al parum amare. Lo excluye, por último, el punto conclusivo que remite también a la motivación de la humildad: "Si así amáis a quien es manso y humilde de corazón no temo en vosotros el más mínimo orgullo" 35. Tenemos aquí el texto de Mt 11,29, básico en la motivación cristológica.

Después de cuanto hemos dicho, cabe dar un paso más en la comprensión de la estructura de la obra. Si el capítulo cincuenta y cuatro $(54,55)$ recapitula la segunda parte de la obra original, es decir, la sección que hemos llamado motivación cristológica de la humildad, ¿no podrá decirse lo mismo del capítulo cincuenta y cinco, aunque referido a la primera parte de la obra? Al menos lo juzgamos probable. Sólo es preciso prestar atención a uno y otro texto. En el capítulo cincuenta y cinco leemos: "todo el amor que habíais pensado encauzar hacia vuestro matrimonio, dádselo a él (Jesucristo)" 36; "en el esposo (uir) que no veis con los ojos, pero contempláis con la fe, no tenéis ningún defecto objetivo que reprender, ni teméis que llegue a ofenderse por una sospecha falsa. Así, pues, si estaríais obligados a amar intensamente a vuestro cónyuge, ¡cuánto más debéis amar a aquel por el cual renunciasteis a tener cónyuge!" 37; "que él posea enteramente en vuestro corazón todo lo que no quisisteis que ocupase un cónyuge" 38 . La idea central es, pues, la de una relación esponsal entre el virgen y Jesucristo, en el marco de una renuncia a tener cónyuge. Ahora bien, con esa idea esponsal comienza la obra: "Que me ayude

34. «... cum tibi modicum dimitti putas, modicum diligas» (XXXVII,38); «ut modicum diligas eum qui te tantum dilexit» (XL,41); «... ut modicum diligat» (XLI,42); «... et noli modicum diligere, quasi a quo tibi modicum dimissum est» (XLII,43); «... ne modicum vobis existimantes dimissum modicum diligatis»2 (LII,53), etc. hasta dieciséis veces.

35. «Sic amantibus mitem et humilem corde nullam uobis superbiam pertimesco» (LV,56 CSEL 41, 301, 1. 15-16).

36. «... et quidquid amoris in nuptias uestras inpendendum habebatis, illi rependite» (LV,56 CSEL 41, 300, 1. 20-21).

37. «Vos in isto (uiro), quem oculos non uidetis et fide conspicitis, non habetis uerum quod reprehendatis, nec eum metuitis, ne de falso forsitan offendatis. Si ergo magnum amorem coniugibus deberetis, eum, propter quem coniuges habere noluistis, quantum amare debetis!» (LV,56 CSEL 41, 303, 1. 7-11).

38. «... totum teneat in animo uestro, quidquid noluistis occupari conubio» (LV,56 CSEL 41, $303,1.12-13)$ 
Cristo, hijo de virgen y esposo de vírgenes, nacido físicamente de seno virginal y unido espiritualmente en desposorio virginal" 39.

De ser cierta la hipótesis que hemos planteado, resultaría una estructura nítida de la obra original en forma de quiasmo. Hela aquí:

1: Cristo, esposo de los vírgenes, preferido a cualquier cónyuge (2,230,30).

2: Cristo, maestro de humildad por su encarnación, pasión y muerte (31,31-37,38a) 40 .

2: Los vírgenes han de amar a Cristo por su belleza, manifestada en la humildad de su encarnación, pasión y muerte $(54,55)$.

1: Los vírgenes han de amar a Cristo, su esposo, preferido a cualquier cónyuge (55,55-56).

\section{El prólogo}

También el prólogo reclama algunas palabras. Tanto Hombert como Lettieri lo consideran una adición posterior, contemporánea a la sección antipelagiana. Nosotros no vemos razones para posponer su composición. De una parte, enlaza perfectamente con el fin de la obra De bono coniugii. En su último capítulo encontramos dicho lo que en este prólogo afirma haber dicho ${ }^{41}$, y ninguno de los autores mencionados considera que esa parte final pertenezca a la segunda etapa. De otra parte, la referencia al matrimonio de los patriarcas, tema inequívocamente antimaniqueo, tendría difícil encaje aquí, pues en el año 412, según la datación propuesta por Hombert, el régimen matrimonial de los patriarcas no preocupaba a san Agustín mayormente, si es que le preocupaba algo. Por último, el considerar la virginidad como un don es idea repetidamente afirmado en la obra, incluso en la parte juzgada primi-

39. «adiuvet Christus, uirginis filius et uirginum sponsus, uirginali utero corporaliter natus, uirginali conubio spiritaliter coniugatus» (II,2 CSEL 41, 236, 1. 10-12).

40. El autor recurre a una inclusión. En el capítulo inicial $(31,31)$ Cristo es presentado como modelo de humildad en razón de su encarnación, con la cita de Fil 2,7-8, y en su capítulo conclusivo (37,38a) Cristo vuelve a aparecer como el modelo de humildad, que prueban los diversos aspectos vinculados a su encarnación.

41. «... in quo (b. coniug.) etiam Christi uirgines commonuimus atque monuimus, ne... contemnant in sui comparatione patres et matres populi dei hominesque illos... ideo meriti inferioris esse arbitrentur...» (I,1, CSEL 41, 235, 1. 2,10); «... at uero continentes... sed sanctorum patrum nuptias... non solum prae suo proposito non contemnant, uerum etiam suo proposito sine dubitatione praeponant» (b. coniug. XXVI,34, 229, 1. 12-20). Es cierto que los textos a que se refiere el texto son los que están o han estado casados, pero a continuación habla ya de los uirgines a los que recomienda la humildad. 
tiva ${ }^{42}$ y no debe ser criterio para considerar al prólogo de un época posterior a los capítulos que le siguen de inmediato.

\section{Conclusión}

Tomamos como punto de partida que la obra De sancta uirginitate fue compuesta en dos etapas. Los argumentos aducidos por P.-M. Hombert nos parecen asumibles. A partir de esa premisa, nuestro estudio nos ha permitido determinar qué parte de la obra actual corresponde a la primera etapa de la redacción y cuál a la segunda. Más en concreto hemos podido ver cómo se integró el texto nuevo en el viejo. Por último, hemos descubierto la estructura literaria utilizada por san Agustín en uno y otro momento.

Por las razones que el mismo san Agustín nos indica ${ }^{43}$, compuso el $D e$ sancta uirginitate. Teniendo ya concluida la obra, llegó a su conocimiento la enseñanza de Pelagio y Celestio sobre la virginidad, y juzgó conveniente oponerse a sus ideas. En lugar de escribir otra, optó por insertar una sección nueva en la obra ya acabada, refutando la excesiva confianza en sí mismos que manifestaban los promotores de las nuevas teorías. Deseando que el nuevo texto encajase lo mejor posible en la obra, optó por interpolarlo después de su segunda parte que contenía una motivación de la humildad sostenida en la persona de Cristo. En fin de cuentas, lo que pretendía era ofrecer una nueva motivación de esa virtud. Pero en la nueva sección la motivará apoyándose en la condición personal de quienes profesan la virginidad. Por otra parte, si ya antes de conocer la controversia pelagiana había sentido la urgencia de vincular la humildad a la persona de Jesucristo, ¿no iba a hacerlo, una vez surgida? Por ello, después de exponer las tres razones que deben estimular la humildad desde la persona de quien vive la virginidad, relacionó cada una de ellas con Jesucristo, recurriendo al quiasmo, según indicamos. Al mismo tiempo, para integrarla aún más en la segunda parte, concluye con la

42. S. uirg. IX,9 CSEL 41, 243, 1. 4 (munus); XXVIII,18, 251, 11 (donum); XXI,21, 255, 1.6 (donum); XXIX,29, 266, 1. 15 (donum); XXXI,31, 268, 1.7 (munus). En el contexto, cuando san Agustín habla de don, se entiende que se trata de un don divino, algo que, por otra parte, afirma explícitamente: cf. XXXI,31 (divinius). Difícilmente se puede sostener pues, la afirmación de Lettieri de que en la primera parte de la obra (según él 2,2-35,35) «nessun ruolo è riservato alla grazia» (L'altro Agostino, p. 219). Por otra parte, no deja de ser significativa la estadística: en la sección que consideramos inicial el sustantivo donum aparece sólo 4 veces -ninguna en los tres últimos capítulos-, mientras que en la sección interpolada, se lee 19 veces. Munus, a su vez, aparece tres veces en la primera parte y sólo una en la segunda.

43. Cf. Retr. 2,22-23. 
cita de Sir 3,18, la misma con que había comenzado aquella, formando así una inclusión ${ }^{44}$.

Una vez intercalada esa sección antipelagiana -lo que en verdad le interesaba-, ya no modificó la que consideramos tercera parte $(54,55-55,56)$. En efecto, a la vez que se echa de menos en ella una referencia a la motivación personal de la humildad, se advierte que toda la reflexión está centrada en la humildad de Cristo. Si, como creen Hombert y Lettieri, los capítulos cincuenta y cuatro y cincuenta y cinco hubiesen sido escritos en la misma época que los capítulos del treinta y siete (en su última parte) al cincuenta y tres, ¿no hubiese reflejado también allí Agustín la nueva problemática? ¿No les hubiese recordado la necesidad de un "mayor" amor al Señor porque les había perdonado más? Es difícil pensar lo contrario.

Ponemos término a estas páginas presentando lo dicho en forma esquemática:

\section{A. Sección original $(2,2-37,38 a ; 54,55-56,57)$ :}

Prólogo (1,1)

Primera parte $(2,2-30,30)$ :

Segunda parte $(31,31-37,38 a)$ :

a) La virginidad, desposorio con Cristo, susuperior al matrimonio.

Tercera parte $(54,55-55,56)$ :

b) Protección de la virginidad: la humildad, motivada en Cristo

b') Exhortación a amar a Jesucristo, maes tro de humildad $(54,55)$.

a') Exhortación a amar a Jesucristo, esposo (55,55-56).

Epílogo (56,57).

\section{B. Sección añadida:}

Motivación personal de la humildad (37,38b-53,54):

a) el virgen ha de amar más porque se le ha perdonado más (37,38b-42-43).

b) el virgen no ha de juzgarse superior al casado $(43,44-46,47)$.

c) el virgen no ha de creerse sin pecado $(47,48-50,50)$.

c') el virgen no ha de creerse sin pecado - Mt 11,27-29 (50,51).

b') el virgen no ha de juzgarse superior al casado - Ap. 14,1-4 (51,52).

a') el virgen ha de amar más porque se le ha perdonado más - Mt 11,29 $(52,53)$. 1. 3-5).

44. Al mismo texto había recurrido ya antes en la parte intercalada (XLIII,44 CSEL 41, 289, 
d) la verdadera virginidad $(53,54)$, con doble inclusión: i) referente a todo el apartado (ref. a Mt 7,13 como en 38,39); ii) referente a la segunda parte de la obra (cita de $\operatorname{Sir} 3,18$ como en 31,31 ).

\section{La obra completa tal como la conocemos:}

Prólogo (1,1).

Primera parte (2,2-30,30): La virginidad, desposorio con Cristo, superior al matrimonio (a).

Segunda parte (31,31-53-54): Protección de la virginidad: la humildad.

1) motivación cristológica de la humildad (31,31-37,38a) (b).

2) motivación personal de la humildad (37,38b-53,54).

Tercera parte $(54,55-55,56)$ :

1) Exhortación a amar a Jesucristo, maestro de humildad $(54,55)$ (b').

2) Exhortación a amar a Jesucristo, esposo (55,55-56) (a').

Epílogo (56,57).

Pío DE LUIS, OSA

Estudio Teológico Agustiniano

Valladolid 